\title{
Beta Carotene Modulates Nitric Oxide Production in the Renal Ischemia/Reperfusion Injury in Rat
}

\author{
Mohammad Badavi, ${ }^{1}$ Mohammad Kazem Gharib Naseri, ${ }^{1}$ Leila Pirmoradi, ${ }^{2}$ and Foruzan Hosseini ${ }^{2,}$ \\ ${ }^{1}$ Physiology Research Center, School of Medicine, Ahvaz Jundishapur University of Medical Sciences, Ahvaz, Iran \\ ${ }^{2}$ Department of Physiology and Pharmacology, School of Medicine, Kurdistan University of Medical Sciences, Sanandaj, Iran \\ "Corresponding author: Foruzan Hosseini, Department of Physiology and Pharmacology, School of Medicine, Kurdistan University of Medical Sciences, Sanandaj, Iran. E-mail: \\ hosseinif@yahoo.com
}

Received 2016 June 25; Accepted 2017 March 18.

\begin{abstract}
Background: Renal ischemia and subsequent reperfusion injury is a major cause of acute renal failure and transplant rejection. Nitric oxide and its metabolites have important role in renal ischemia/reperfusion injury. Beta carotene as an antioxidant effectively scavenges toxic metabolites of nitric oxide. Our previous study has shown that beta carotene pretreatment protects kidney against ischemia/reperfusion injury.

Objectives: In this experimental study we investigated whether effect of beta carotene is causally linked with nitric oxide signal transduction.

Methods: In this experimental study, male adult Wistar rats (250 - $300 \mathrm{~g}$ ) were exposed to 45 minutes of renal ischemia followed by 4 hours of reperfusion. Beta carotene $\left(10,30\right.$ and $\left.100 \mathrm{mg} \mathrm{kg}^{-1}\right)$ or vehicle was administered for 5 days prior to ischemia. Nitrite and nitrate were measured in the urine sample. Blood Flow and blood pressure were monitored during I/R period.

Results: $\mathrm{I} / \mathrm{R}$ decreased $(\mathrm{P}<0.001)$ urinary nitrite - nitrate and renal blood flow. Beta carotene pretreatment increased them $(\mathrm{P}<$ $0.05-\mathrm{P}<0.001)$, although not by all doses. Blood pressure was not affected by beta carotene.

Conclusions: Since beta carotene administration improved renal blood flow and reduced the injury, it seems that beta carotene exerts some of its protective effects, probably by modulating of nitric oxide system.
\end{abstract}

Keywords: Beta Carotene, Ischemia/Reperfusion, Nitric Oxide, Antioxidant, Blood Flow

\section{Background}

Renal ischemia and subsequent reperfusion (I/R) injury is an unavoidable consequence of kidney transplantation, which also occurs in many other clinical situations. The results of this phenomenon vary from acute kidney injury to acute and chronic transplant rejection [1].

$\mathrm{I} / \mathrm{R}$ injury is a complex phenomenon involving multifactorial and interdependent mechanisms [2]. Imbalance between local tissue oxygen supply and demand results in accumulation of metabolites that could harm the tubular epithelial cells, eventually leads to death by apoptosis and necrosis [3].

Nitric oxide(NO) and its metabolites play an important role in I/R injury [4]. NO is thought to exert both protective and deleterious effects depending on the generating enzyme: the generation of NO by inducible NO synthase (iNOS) contributes to renal cell injury due to infiltration with inflammatory cells, by direct DNA damage or by apoptotic effects. On the other hand, reduced activity of endothelial NOS (eNOS) contributes to renal impairment due to endothelial dysfunction and consecutive renal vasoconstriction [5].
Beta-carotene, the most abundant form of provitamin A, powerfully scavenges free radicals [6] and its consumption can reduce the risk of various disorders, like cardiac disease and cancer [7].

We have previously shown that beta carotene pretreatment protects kidney against I/R injury by restoring of antioxidants and reduction of lipid peroxidation in renal tissue [8].

Inhibition of nitric oxide synthase reduces renal $I / R$ [9]. It has been shown that beta carotene can inhibit iNOS and thereby possesses anti-inflammatory activity [10]. Another study reported that beta carotene effectively scavenges toxic NO metabolites like nitrogen dioxide and peroxynitrous acid [11].

\section{Objectives}

So in this experimental study we investigated whether protective effect of beta carotene on the renal $I / R$ injury is causally linked with nitric oxide signal transduction. 


\section{Methods}

Animals: in this experimental study, male Wistar rats (250 -300 g) were housed in a light-controlled room with 12 hours light-dark cycle and were allowed ad libitum access to food and water. The experimental protocols were approved by the ethic committee of Ahvaz Jundishapur University of Medical Sciences.

Experimental protocols: animals were randomly divided into five groups $(n=7)$ : group 1 , all surgical procedures were carried out except clamping of the renal pedicles (Sham); group 2, animals received Tween-80 in physiologic saline ( $4 \mathrm{~mL} \mathrm{~kg}^{-1}$, ip) for 5 days and then $\mathrm{I} / \mathrm{R}$ was performed (I/R); groups 3, 4 and 5 which received beta carotene at 10, 30 and $100 \mathrm{mg} \mathrm{kg}^{-1}$ via intraperitoneal injection, respectively (as BC10 + I/R; BC30 + I/R and BC100 + $I / R$ ) [12-14], for 5 days prior to $I / R$ induction [15]. In the day of experiment, animals were anaesthetized with a combination of xylazine (20 $\mathrm{mg} \mathrm{kg}^{-1}$, ip) and ketamine (100 mg $\mathrm{kg}^{-1}$, ip). Anesthesia was maintained by supplementary doses of anesthetics. Body temperature was recorded rectally and maintained at $37^{\circ} \mathrm{C}$ by using a thermostatic blanket (Harvard Apparatus, UK). Tracheostomy was performed to maintain airway patency and to facilitate spontaneous respiration. The right femoral artery was cannulated (PE50) to measure mean arterial pressure (MAP) continuously (Powerlab system, ADInstruments, Australia). The right femoral vein was cannulated for anesthetics administration and heparinized saline infusion at $2-4 \mathrm{~mL} \mathrm{~kg}^{-1} \mathrm{~h}^{-1}$. Bladder was cannulated for collection of urine sample. The renal pedicles, containing the artery, vein, and nerve supply of each kidney were isolated. After 45 minutes stabilization period, I/R injury was induced by clamping both renal vascular pedicles for 45 minutes, followed by 4 hours of reperfusion [16]. Cortical blood flow of the kidney was monitored by Laser Doppler (Moor instruments) prior to ischemia and during reperfusion period. Urine sample was collected during reperfusion period and stored at $-20^{\circ} \mathrm{C}$ until analysis.

NO assay: nitrate and nitrite (NOx) in the plasma level were determined to measure the NO generation. Detection of NOx was performed using the nitrate/nitrite colorimetric assay kit obtained from Cayman chemical company (Ann Arbor, MI, USA) in a 96-well plate according to the manufacturer's protocol. Urinary NOx excretion is expressed as $\mu \mathrm{M}$ NOx to $\mathrm{mM}$ Creatinine $(\mathrm{Cr})$ ratio.

Creatinine assay: urinary $\mathrm{Cr}$ concentration was measured spectrophotometrically (Ultrospec 3000, Pharmacia Biotech, USA) using commercial kit (DarmanKave, Iran).

Statistical analysis: given as means \pm SEM, data were analyzed by using statistical package for social sciences (SPSS, version 17) for Windows software. For NOx levels statistical significance was determined by ANOVA test followed by Dunnett's test. Blood flows and blood pressures were compared by repeated measures ANOVA and Bonferroni test. AP $<0.05$ was considered statistically significant.

\section{Results}

Concentration of both nitrite and nitrate as an established marker of NO generation was determined. The NOx production is expressed as a ratio of $\mathrm{NOx} / \mathrm{Cr}$ for more accuracy. Renal I/R injury resulted in a non-significant increase of NOx excretion compared to the sham group (Figure 1). Although beta carotene pretreatment strongly increased $\mathrm{NOx} / \mathrm{Cr}$ ratio in $\mathrm{BC} 30+\mathrm{I} / \mathrm{R}$ and $\mathrm{BC} 100+\mathrm{I} / \mathrm{R}$ groups $(\mathrm{P}<0.05$ and $\mathrm{P}<0.01$ ), this ratio was unaffected by beta carotene pretreatment at the $10 \mathrm{mg} / \mathrm{kg}$ dose.

The MAP results of all groups are shown in Figure 2. There were no significant differences in the initial values of MAP between groups. Induction of ischemia immediately increased MAP in all groups. MAP returned to the baseline value in $40^{\text {th }}$ minutes of reperfusion period and did not change up to the end of experiment. Beta carotene pretreatment had no significant effect on MAP at any doses.

Figure 1. Effect of Beta Carotene Pretreatment at 10,30, and $100\left(\mathrm{mg} \mathrm{kg}^{-1}\right)$ on Urinary Nitrite/Nitrate (NOx) Excretionin Rat

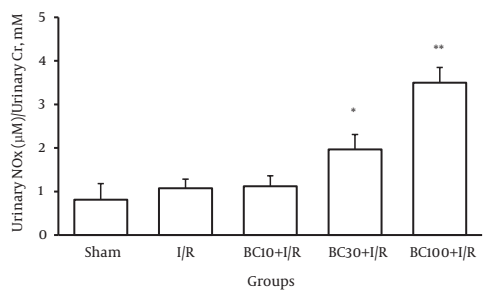

Effect of beta carotene pretreatment at 10,30 , and $100\left(\mathrm{mg} \mathrm{kg}^{-1}\right)$ on urinary nitrite/nitrate (NOx) excretion in rat. NOxexcretion is given in $\mu \mathrm{MNOx} / \mathrm{mM} \mathrm{Cr}$. Values expressed as mean \pm SEM. ${ }^{*}$ and ${ }^{* *}$ Significant difference vs. I/R group, $\mathrm{P}<0.05$ and $\mathrm{P}<0.01$ respectively. (One-way ANOVA followed by Dunnett's test).

Figure 3 indicates the renal blood flow (RBF) in all groups. After releasing the clamp, RBF started to increase steadily but it did not reach to the baseline value in any groups. RBF values were significantly higher in $\mathrm{BC} 30+\mathrm{I} / \mathrm{R}$ and $\mathrm{BC} 100+\mathrm{I} / \mathrm{R}$ groups than respective values in $\mathrm{I} / \mathrm{R}$ group.

\section{Discussion}

This study designed to assess the probable role of NO in the protective mechanisms of beta carotene in the renal $\mathrm{I} / \mathrm{R}$ injury. The results showed an increase in NO production after induction of $\mathrm{I} / \mathrm{R}$, remarkably in the beta carotene 
Figure 2. Mean Arterial Pressure During I/R Injury in Different Groups

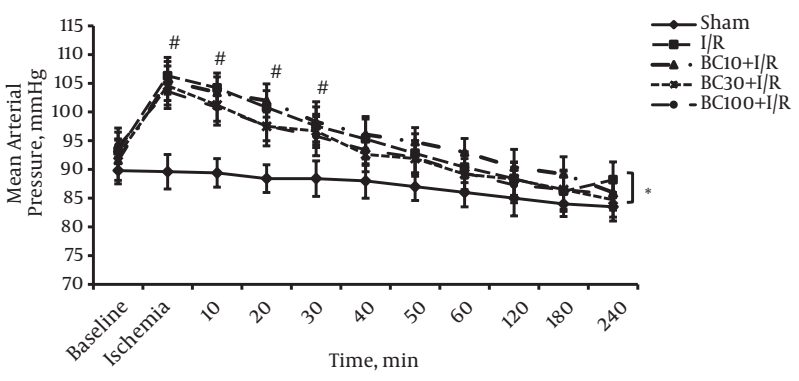

Mean arterial pressureduring $\mathrm{I} / \mathrm{R}$ injury in different groups. Values expressed as mean \pm SEM. * Significant difference vs. sham group, $\mathrm{P}<0.05$. \# Significant difference vs. Its basic values of the same group, $\mathrm{P}<0.05$ (ANOVA followed by Bonferronior Dunnett's test).

Figure 3. Cortical Renal Blood Flow During I/R Injury in Different Groups

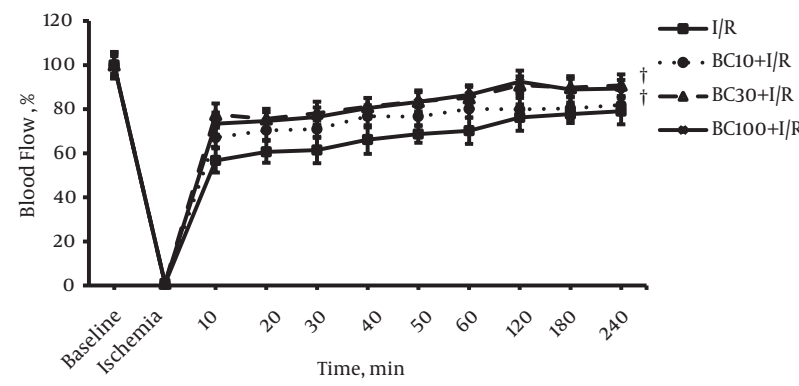

Cortical renal blood flow during $\mathrm{I} / \mathrm{R}$ injury in different groups. Values expressed as mean \pm SEM in respect of the basic value. $\dagger$ Significant difference vs. I/R group, $\mathrm{P}<$ 0.05. (ANOVA followed by Bonferroni test).

treated groups and concomitant increase in blood flow despite relatively stable blood pressure.

Ischemia (cessation of blood flow), followed by reperfusion (re-establishment of blood flow), causes characteristic injury to organs and tissues [17]. Different mechanisms are involved in the renal $I / R$ injury including hypoxia, inflammatory responses and free radicals production [18]. Many studies revealed the role of NO and its metabolites in mechanism of I/R injury [19-21].

Three isoforms of nitric oxide synthase (NOS) produce NO: endothelial NOS (eNOS) and neuronal NOS (nNOS), collectively known as constitutive NOS (cNOS), are expressed in the renal vasculature and macula densa, respectively. Inducible NOS (iNOS) has been found in segments of the renal tubule, glomerulus, and interlobular and arcuate arteries of normal rat kidneys [9]. The beneficial effects of eNOS in maintenance of renal function like sodium reabsorption in proximal tubule were reported $[22,23]$. It also has been reported that NO produced by eNOS can dilate the pre-glomerular arteries and thereby increases renal blood flow [24]. On the other hand, enhanced iNOS activity can lead to renal dysfunction [21].

Collectively, an imbalance between the expression and activity of eNOS and iNOS (a decline in eNOS activity with a concurrent increase in iNOS expression) is therefore responsible for pathophysiology of I/R injury [17].

Though our results showed a little increase in NO generation after I/R induction, interestingly beta carotene pretreatment enhanced it more. However discrimination between eNOS and iNOS derived NO production is not possible based on our data.

It has been shown that NO can interact with superoxide anion to generate the prooxidant species such as peroxynitrite, an important agent which causes lipid peroxidation of cellular membranes [24]. Under the acidic conditions that prevail during $\mathrm{I} / \mathrm{R}$, it converts to peroxynitrite and subsequently to other toxic compounds like nitryl cation, nitrogen dioxide and hydroxyl radical [25].

In our previous studies beta carotene pretreatment could attenuate I/R injury and restore endogenous antioxidants like glutathione and superoxide dismutase $[8,26]$. This is in accordance with other reports that introduce beta carotene as an effective scavenger of toxic reactive nitrogen species like: nitrogen dioxide and peroxynitrous acid [27, 28]. Then we conclude that beta carotene pretreatment in higher doses used in this study, despite more NO generation, could scavenge toxic NO metabolites effectively.

Our results showed that beta carotene pretreatment could enhance RBF, implying a reduction in vascular resistance probably by action of NO. These findings lead us to this idea that beta carotene stimulated eNOS more than iNOS. Another finding of our study was the stability of blood pressure in most of the reperfusion time. Then enhancement of RBF could not be due to changes in blood pressure. These results are in accordance with previous study [24] which notified L-arginine (precursor of NO) has a tendency to exert a beneficial effect on renal damage during I/R in rats. Moreover, L-NAME (inhibitor of NOS) seems to worsen the renal damage probably due to reduction of NO production.

\subsection{Conclusions}

The findings of this study indicate that pretreatment of beta carotene had a protective role in I/R injury of the kidney by increasing of RBF due to stimulation of NO generation probably further by eNOS isoform and by scavenging of toxic NO metabolites. 


\section{Acknowledgments}

This study was supported by grant number PRC 21 from Ahvaz Jundishapur University of Medical Sciences.

\section{Footnotes}

Authors' Contribution: Mohammad Badavi and Mohammad Kazem Gharib Naseri developed the original concept and designed experiments, advised on surgical protocol and conducted statistical analysis. Leila Pirmoradi interpreted data and made critical revision of the manuscript. Foruzan Hosseini performed all surgical procedures and biochemical assays and wrote the manuscript.

Conflict of Interests: There is no conflict of interest. Funding/Support: This study was supported by Ahvaz Jundishapur University of Medical Sciences.

\section{References}

1. Saat TC, van den Akker EK, I. Jzermans JN , Dor FJ, de Bruin RW. Improving the outcome of kidney transplantation by ameliorating renal ischemia reperfusion injury: lost in translation?. J Transl Med. 2016;14:20. doi: 10.1186/s12967-016-0767-2. [PubMed: 26791565].

2. de Groot H, Rauen U. Ischemia-reperfusion injury: processes in pathogenetic networks: a review. Transplant Proc. 2007;39(2):481-4. doi: 10.1016/j.transproceed.2006.12.012. [PubMed: 17362763].

3. Bonventre JV, Yang L. Cellular pathophysiology of ischemic acute kidney injury. J Clin Invest. 2011;121(11):4210-21. doi: 10.1172/JCI45161. [PubMed: 22045571].

4. Waz WR, Van Liew JB, Feld LG. Nitric oxide metabolism following unilateral renal ischemia/reperfusion injury in rats. Pediatr Nephrol. 1998;12(1):26-9. doi: 10.1007/s004670050397. [PubMed: 9502563].

5. Betz B, Schneider R, Kress T, Schick MA, Wanner C, Sauvant C. Rosiglitazone affects nitric oxide synthases and improves renal outcome in a rat model of severe ischemia/reperfusion injury. PPAR Res. 2012;2012:219319. doi: 10.1155/2012/219319. [PubMed: 22448163].

6. Sarada SK, Dipti P, Anju B, Pauline T, Kain AK, Sairam M, et al. Antioxidant effect of beta-carotene on hypoxia induced oxidative stress in male albino rats. J Ethnopharmacol. 2002;79(2):149-53. doi: 10.1016/S0378-8741(01)00360-9. [PubMed: 11801375].

7. Hathcock JN. Vitamin and mineral safety. 3rd ed. Washington, D.C Council for Responsible Nutrition (CRN); 2014. pp. 25-31.

8. Hosseini F, Naseri MK, Badavi M, Ghaffari MA, Shahbazian H, Rashidi I. Effect of beta carotene on lipid peroxidation and antioxidant status following renal ischemia/reperfusion injury in rat. Scand J Clin Lab Invest. 2010;70(4):259-63. doi: 10.3109/00365511003777810. [PubMed: 20380616].

9. Mark LA, Robinson AV, Schulak JA. Inhibition of nitric oxide synthase reduces renal ischemia/reperfusion injury. J Surg Res. 2005;129(2):236-41. doi:10.1016/j.jss.2005.06.019. [PubMed:16140334].

10. Bai SK, Lee SJ, Na HJ, Ha KS, Han JA, Lee H, et al. beta-Carotene inhibits inflammatory gene expression in lipopolysaccharide-stimulated macrophages by suppressing redox-based NF-kappaB activation. Exp Mol Med. 2005;37(4):323-34. doi: 10.1038/emm.2005.42. [PubMed: 16155409].

11. Kikugawa K, Hiramoto K, Tomiyama S, Asano Y. beta-Carotene effectively scavenges toxic nitrogen oxides: nitrogen dioxide and peroxynitrous acid. FEBS Lett. 1997;404(2-3):175-8. doi: 10.1016/S00145793(97)00124-5. [PubMed: 9119059].
12. Singh P, Bhargava VK, Garg SK. Effect of melatonin and beta-carotene on indomethacin induced gastric mucosal injury. Indian J Physiol Pharmacol. 2002;46(2):229-34. [PubMed: 12500499].

13. Manda $\mathrm{K}$, Bhatia AL. Role of $\beta$-carotene against acetaminopheninduced hepatotoxicity in mice. Nutrition Research. 2003;23(8):1097103. doi:10.1016/s0271-5317(03)00103-9.

14. Manda K, Bhatia AL. Pre-administration of beta-carotene protects tissue glutathione and lipid peroxidation status following exposure to gamma radiation. J Environ Biol. 2003;24(4):369-72. [PubMed: 15248648].

15. Matos HR, Marques SA, Gomes OF, Silva AA, Heimann JC, Di Mascio P, et al. Lycopene and beta-carotene protect in vivo iron-induced oxidative stress damage in rat prostate. Braz J Med Biol Res. 2006;39(2):203-10. [PubMed: 16470307]

16. Nesic Z, Todorovic Z, Stojanovic R, Basta-Jovanovic G, Radojevic Skodric S, Velickovic R, et al. Single-dose intravenous simvastatin treatment attenuates renal injury in an experimental model of ischemia-reperfusion in the rat. J Pharmacol Sci. 2006;102(4):413-7. doi: 10.1254/jphs.SCE06002X. [PubMed: 17130671].

17. Chatterjee PK. Novel pharmacological approaches to the treatment of renal ischemia-reperfusion injury: a comprehensive review. Naunyn Schmiedebergs Arch Pharmacol. 2007;376(1-2):1-43. doi:10.1007/s00210007-0183-5. [PubMed: 18038125].

18. Williams P, Lopez H, Britt D, Chan C, Ezrin A, Hottendorf R. Characterization of renal ischemia-reperfusion injury in rats.JPharmacol Toxicol Methods. 1997;37(1):1-7. doi: 10.1016/S1056-8719(96)00141-4. [PubMed: 9086282].

19. Yaqoob M, Edelstein CL, Wieder ED, Alkhunaizi AM, Gengaro PE, Nemenoff RA, et al. Nitric oxide kinetics during hypoxia in proximal tubules: effects of acidosis and glycine. Kidney Int. 1996;49(5):1314-9. doi:10.1038/ki.1996.187. [PubMed: 8731096].

20. Goligorsky MS, Brodsky SV, Noiri E. Nitric oxide in acute renal failure: NOS versus NOS. Kidney Int. 2002;61(3):855-61. doi:10.1046/j.1523 1755.2002.00233.x. [PubMed: 11849438].

21. Tripatara P, Patel NS, Webb A, Rathod K, Lecomte FM, Mazzon E, et al. Nitrite-derived nitric oxide protects the rat kidney against ischemia/reperfusion injury in vivo: role for xanthine oxidoreductase. J Am Soc Nephrol. 2007;18(2):570-80. doi: 10.1681/ASN.2006050450. [PubMed: 17202421].

22. Ortiz PA, Garvin JL. Role of nitric oxide in the regulation of nephron transport. Am J Physiol Renal Physiol. 2002;282(5):F777-84. doi: 10.1152/ajprenal.00334.2001. [PubMed: 11934686].

23. Liang M, Knox FG. Production and functional roles of nitric oxide in the proximal tubule. Am J Physiol Regul Integr Comp Physiol. 2000;278(5):R1117-24. [PubMed:10801277].

24. Rhoden EL, Rhoden CR, Lucas ML, Pereira-Lima L, Zettler C, Bello-Klein A. The role of nitric oxide pathway in the renal ischemia-reperfusion injury in rats. Transpl Immunol. 2002;10(4):277-84. doi:10.1016/S09663274(02)00079-5. [PubMed: 12507399].

25. Beckman JS. Oxidative damage and tyrosine nitration from peroxynitrite. Chem Res Toxicol. 1996;9(5):836-44. doi: 10.1021/tx9501445. [PubMed: 8828918].

26. Hosseini F, Naseri MK, Badavi M, Ghaffari MA, Shahbazian H, Rashidi I. Protective effect of beta carotene pretreatment on renal ischemia/reperfusion injury in rat. PakJ Biol Sci. 2009;12(16):1140-5. doi: 10.3923/pjbs.2009.1140.1145. [PubMed: 19899325].

27. Panasenko OM, Sharov VS, Briviba K, Sies H. Interaction of peroxynitrite with carotenoids in human low density lipoproteins. Arch Biochem Biophys. 2000;373(1):302-5. doi: 10.1006/abbi.1999.1424. [PubMed:10620353].

28. Pannala AS, Rice-Evans C, Sampson J, Singh S. Interaction of peroxynitrite with carotenoids and tocopherols within low density lipoprotein. FEBS Lett. 1998;423(3):297-301. doi: 10.1016/S0014-5793(98)001082. [PubMed: 9515727] 